\title{
Examining the potential for energy-positive bulk- water infrastructure to provide long-term urban water security: A systems approach $\underline{\text { Oz Sahin }}{ }^{\mathrm{a}, \mathrm{b}}$, Raymond Siems $^{\mathrm{a}, \mathrm{b}}$, Russell G. Richards ${ }^{\mathrm{b}, \mathrm{c}}$, Fernanda Helfer ${ }^{\mathrm{a}}$, and Rodney A. Stewart ${ }^{\mathrm{a}}$
}

\author{
${ }^{a}$ Griffith School of Engineering, Griffith University, QLD, Australia (o.sahin@griffith.edu.au) \\ ${ }^{b}$ Griffith Climate Change Response Program, Systems Modelling Group, Griffith University, QLD, \\ Australia \\ 'School of Agriculture and Food Sciences, University of Queensland, QLD, Australia
}

\begin{abstract}
:
Urban centres are increasingly requiring more water than existing groundwater and surface water sources can supply. Water authorities must consider energy intensive supply alternatives such as recycling and desalination, leading to a water-energy-climate conundrum. In this study, a systems perspective of the water-energy-climate nexus is applied to South-East Queensland (SEQ), Australia. Under a changing climate, SEQ is predicted to experience reduced reservoir inflows and increased evaporation rates, which will consequently lead to reduced water availability. To exacerbate this issue, anticipated high population growth in SEQ will increase water demand, putting even more stress on the traditional water supply sources. Clearly, there is a strong incentive to pursue solutions that increase water security without contributing to anthropogenic climate change. Using a system dynamics model, the water balance of the bulk water supply system is evaluated over a 100-year life cycle. The outputs of the model are used to investigate potential management and infrastructure options available to SEQ
\end{abstract}


for adapting to increased water scarcity. The historical rainfall patterns of SEQ requires significant contingency to be built into surface water capacity in order to mitigate low rainfall years, and provide adequate water security. In contrast, reverse osmosis $(R O)$ desalination plants do not require this excess capacity because they are rain-independent. However, RO has high energy consumption and associated greenhouse gas emissions when operating and their potential long periods of redundancy due to periods of sufficient surface water supplies remain unresolved issues. The model demonstrates that dual purpose pressure retarded osmosis desalination plants offer a potential solution, by providing water security at a lower cost than surface water reservoir augmentation, while offsetting energy use through renewable energy generation when $\mathrm{RO}$ plants would otherwise be sitting idle. Potentially this technology represents a future sustainable solution to overcome water security concerns.

Keywords: Desalination; renewable energy; water resource management; system dynamics; water supply and GHG; complex systems

\section{INTRODUCTION}

\subsection{Global Context}

Global demand for energy and water is ever increasing, yet an era is beginning where water and energy consumption must decrease to avoid worsening anthropogenic climate change, unless renewable energy sources comprise a greatly increased share of energy production. The impacts of climate change will be channelled primarily through the water cycle, with consequences that could be large and uneven across the globe (World Bank, 2016). Water-related climate risks cascade through food, energy, urban, and environmental systems (World Bank, 2016). Without a fundamental shift in production processes, a projected 55\% more water (WWAP, 2014) and 40\% more energy (IEA, 2014) would be required to support future food demands by 2050 (UNDESA, 2013).

Population and standard of living trends indicate that global energy demand will triple from 2011 levels to approximately 1500 EJ in 2050 (Siirola, 2014). Similarly, global water demand is expected to approximately double by 2050 , even with significant efficiency gains (Hejazi et al., 2014). Freshwater supply is already unable to meet demand for at least part of the year for more than $33 \%$ of the world 
(WWAP, 2015). Similarly, in its latest report, the World Bank predicts that, within the next three decades, demand for water from agriculture could increase by $50 \%$, and for urban uses by between $50 \%$ and $70 \%$. Meanwhile, water consumption of energy sector by 2035 is estimated to increase by $85 \%$ (World Bank, 2016). While the world is expected to experience a surge in demand for water, under changing climate it will also face a less reliable water supply. Satisfying the concurrent increases in demand for water for food production, energy generation, urban growth, and ecosystem services would be impossible unless these sources are managed more effectively. Clearly, as water demand increases, it will likely become necessary to employ desalination in regions that currently derive most supply from natural sources, especially with current groundwater abstraction rates being unsustainable (UNESCO, 2012). Already there are more than 18,000 desalination plants installed worldwide, in over 150 countries, with more than $300 \mathrm{M}$ people relying on desalination for their daily water needs (IDA, 2015). Reverse osmosis (RO) is the dominant technology for new installations (IDA, 2015). Water desalination with RO could significantly increase projected global energy demand beyond the aforementioned projections (Siirola, 2014); the energy intensity of removing soluble salts from water is a major issue (Elimelech and Phillip, 2011; Schallenberg-Rodríguez et al., 2014). However, the challenge of meeting future water demands whilst also dealing with, and reducing contributions to, climate change is very complex, akin to what has been described as a super wicked problem (Lazarus, 2009).

It is imperative that water supply is increased in line with demand whilst also reducing the contribution of feedback pathways that exacerbate energy use and climate change. Under the existing waterenergy-climate system, increased water extraction leads to "more greenhouse gas (GHG) emissions". Conversely, the goals and targets of sustainable development broadly demand that more water means "no more GHG emissions". Of the United Nations 17 Sustainable Development Goals, six relate directly to the water-energy-climate nexus (UN, 2015). New technology, policy and optimised infrastructure portfolios must be developed to meet these goals, which is the focus of this exploratory research. Consequently the aspiration of sustainability requires a transformation in system behaviour from one where increased water use currently drives energy use and climate change (reinforcing loop) to one that mitigates energy use and climate change (balancing loop). 


\subsection{Australian Context}

Australia is characterised by climatic extremes. It is the driest inhabited continent and has the highest per capita surface water storage capacity of any country in the world (ABS, 2012). At a glance, it may appear to have ample water supply, only utilising roughly $5 \%$ of its total freshwater resources (OECD, 2015a). However, due to its vast size and extensive expanses of desert, there is uneven spatial distribution of population, with high concentrations in coastal areas extracting more than $50 \%$ of total renewable supply annually (Hatton et al., 2011). Until recently, Australia's water supply relied solely on precipitation and surface runoff storage. However, possessing a large storage capacity that is dependent on rainfall patterns does not provide water security. This has been observed during recent droughts, such as the Millennium drought which shaved at least 1\% off the country's GDP in 2006/2007 (World Economic Forum Water Initiative, 2011). During this time, unprecedented water scarcity was experienced with inflows reduced by 70\% (Pittock and Connell, 2010). In South-East Queensland (SEQ) in 2007, the result of six consecutive years of decline in the total storage level due to low rainfall caused the accessible volume in the region to fall below $40 \%$ of capacity. The primary supply reservoir for SEQ's capital city Brisbane fell to $15 \%$ capacity (SEQ Water, 2016). Subsequently, more than two M people in the region were subject to the highest level of water restrictions available, reducing residential consumption from approximately $450 \mathrm{~L}$ per person per day to $140 \mathrm{~L}$ per person per day in 2007 (QWC, 2010).

Pressure on water supply availability is expected to increase over time, led by a changing climate and high population and economic growth in Australia. Annual surface runoff, currently the main source of surface water storage systems, is expected to decrease in all Australian capital cities under an increase of $1^{\circ} \mathrm{C}$ in global average temperatures, which is expected to occur by 2030 (IPCC, 2014a). In SEQ, annual surface runoff is predicted to decrease by between 5 and $30 \%$ in this scenario, depending on location. Under $2^{\circ} \mathrm{C}$ global average warming, these decreases will approximately double (Post et al., 2011). In addition, open water evaporation is expected to increase in the SEQ region, reducing the availability of surface water. Evaporation rates from reservoirs are expected to be $8 \%$ higher in 2040 , and $15 \%$ higher in 2080 in comparison with the baseline long-term average evaporation rates observed in the SEQ region (Helfer et al., 2012). The main driver of these increases in evaporation is the 
increased air temperatures. Warmer air temperatures will also see an increase in water demand. In SEQ it is well established that higher temperatures lead to increased household water demand (QWC, 2010, 2012; Willis et al., 2013).

With these factors considered, the Intergovernmental Panel on Climate Change (IPCC, 2014a) lists constraints on water resources in southern Australia as one of eight key risks facing Australasia due to climate change. However, it also lists this risk as one that 'can be reduced substantially by globally effective mitigation combined with adaptation' (IPCC, 2014a, 1375).

With the objective of achieving water security through water resources policy and management, adaptation began in earnest following the aforementioned drought affecting South-Eastern Australia. Water authorities have increasingly sought rain-independent supply alternatives such as large-scale recycling and seawater desalination for both base load supply and rapid drought response. SEQ was the second Australian region to invest in a reverse osmosis (RO) desalination plant, in 2009. There are now six large-scale RO desalination plants across Australia representing total capital costs in excess of $A \$ 10$ billion (Turner et al., 2016).

According to El Saliby et al. (2009), the predominant desalination technology in Australia is RO desalination $(68 \%)$, followed by vapour compression distillation $(23 \%)$ and by multi-stage flash distillation (7\%). RO desalination is responsible for $90 \%$ of the desalinated water in Queensland - the state where this study was conducted. Even though RO desalination remains as an energy-intensive process with high installation and operation costs, through significant technological improvements in the last decade, the costs have been considerable. Factors that contributed to the reduced costs were the development of membranes that can operate for a longer duration, the use of renewable energy to supply part of the energy requirements, and the development of energy recovery devices to reduce power consumption (Wilf, 2014). The economics of seawater desalination and its potential application in Australia were studied by Winter et al. (2002), who found that RO is the most economical technology to be used in Australia due to its lower energy consumption, leading to lower unit water costs, when compared to the other desalination technologies. 
While rain-independent bulk supply sources such as $\mathrm{RO}$ desalination significantly enhance the resilience of the SEQ water supply to higher climate variability, they also adversely contribute to the GHG problem due to their high energy requirements, usually provided by fossil fuel sources (Elimelech and Phillip, 2011).

Australia has long been the largest emitter of greenhouse gases per capita in the world, with emissions estimated at $25 \mathrm{t}$ per person per year for the last decade, double the OECD average (OECD, 2015b). Fossil fuels are the source for over $98 \%$ of energy production (primary energy produced before consumption or transformation) in the Australia economy (Department of Industry and Science, 2015). Yet, as outlined by the IPCC (2014b), Australia stands to lose more than most OECD countries with global warming. It is counterintuitive for the nation to achieve water security through methods such as desalination if this means exacerbating an already extreme level of GHG emissions and fossil fuel reliance.

\subsection{Pressure retarded osmosis as a potential energy offset}

A potential means of addressing the high-energy intensity of traditional $\mathrm{RO}$ desalination plants is the use of pressure retarded osmosis (PRO) to generate renewable energy from salinity gradients, and hence offset part of the energy requirements of RO desalination plants. Osmotic power with PRO is induced by the pressure gradient created across a membrane separating solutions of different salinities. When seawater is desalinated, a significant quantity of brine is generated. According to Helfer and Lemckert (2015), the salinity gradient between this brine and freshwater, treated wastewater or seawater, is a potential source of renewable energy that could be explored via PRO to generate useful power for the desalination process. As such, PRO has the potential to indirectly reduce the environmental impact of the desalination process by reducing its reliance on fossil fuel consumption and consequently reduce the discharge of greenhouse gases into the atmosphere. Moreover, the use of PRO could significantly enhance community perceptions towards, and lower the life cycle costs of, desalinated water. A diagram of a PRO-assisted RO desalination plant is presented in Figure 1. 


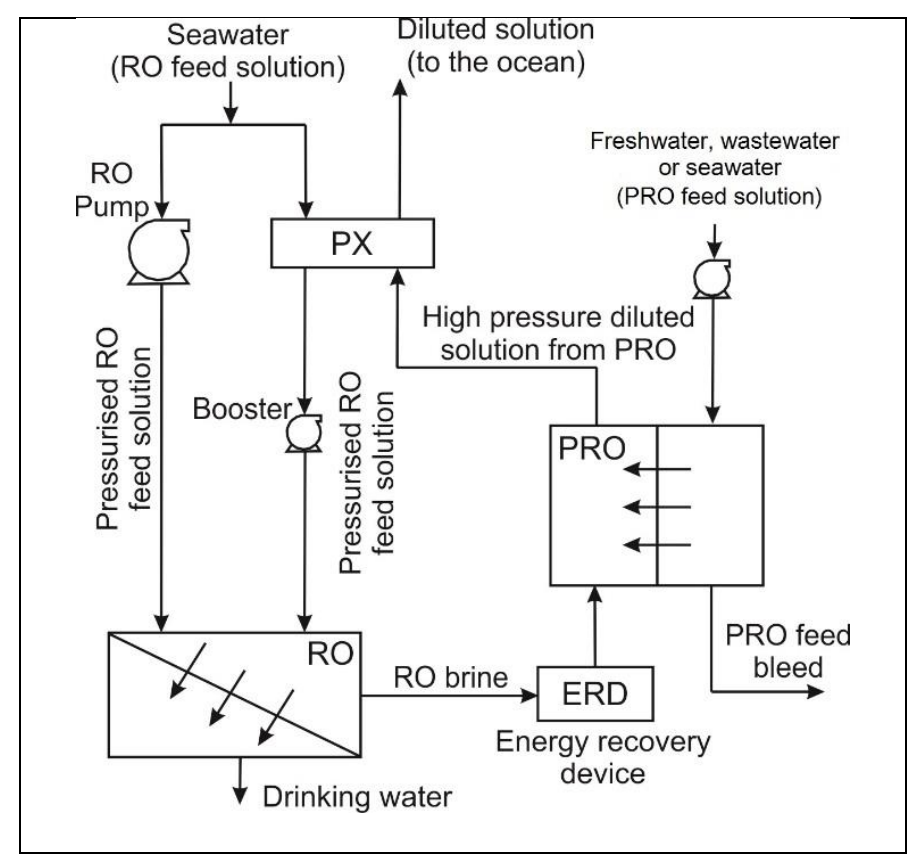

Figure 1. Schematics of a PRO-assisted RO desalination plant. In a conventional RO plant, the RO brine existing in the RO module would flow straight through the pressure exchanger (PX) (instead of entering the PRO module), where its energy would be transferred to the incoming RO feed solution (seawater)

A problem facing government and water businesses in Australia is that in rainfall periods when reservoir levels are full and potentially overflowing, their portfolio of desalination plants have limited value and are put to standby mode. The use of the idle desalination infrastructure to generate osmotic power from the mixing of seawater and freshwater would allow these desalination plants in standby mode to generate electricity through PRO when they are not being used for potable water production (Helfer et al., 2013).

Currently, desalination plants consume $3-4 \mathrm{kWh} \mathrm{m}^{-3}$ when producing freshwater from seawater (Hoang et al., 2009). Thorsen and Holt (2009) reported that up to $0.74 \mathrm{kWh} \mathrm{m}^{-3}$ could be potentially generated from the mixing of seawater and freshwater, providing an attractive figure for power offset in desalination. As a reference point, Kenway et al. (2008) reported that water supplying Brisbane, SEQ's major city, is pumped to homes and treated for consumption at an energy cost of $0.67 \mathrm{kWh} \mathrm{m}^{-3}$. For the Gold Coast, the second largest SEQ city, the figure is a lower $0.22 \mathrm{kWh} \mathrm{m}^{-3}$, virtue of the large gravity head between the Hinze Dam and simpler treatment requirements. In water supply and wastewater 
treatment, (Kenway et al., 2008) found that $98 \%$ of the energy used was generated in coal-fired power stations, while the Gold Coast figure was virtually $100 \%$.

The use of renewable energy sources to power RO desalination systems is growing considerably. The main sources used in Australia are solar and wind power (Rowlinson et al., 2012). The main drawback of these renewable energy sources, however, is the intermittent supply of power, which is undesired in RO desalination systems, in which a constant supply of power is preferable. This is the main reason why PRO is being widely suggested as a means to power RO desalination systems (e.g. Helfer and Lemckert (2015)). In addition to providing uninterrupted supply of power and offsetting GHG emissions, PRO offers an opportunity to minimise the negative impacts of the discharge of RO brine in the ocean, by diluting it to seawater concentration prior to discharge. A study conducted by Straub et al. (2016) has demonstrated that the RO-PRO system would theoretically be able to reduce the minimum specific energy consumption of $\mathrm{RO}$ desalination by one half if the feed solution was available at a significant quantity. Given that energy is the most important component of the operational costs of $\mathrm{RO}$ desalination systems, it is reasonable to assume that the energy reduction provided by PRO would translate into significant savings in the desalination process. It is important to note, however, that although the PRO technology is being widely suggested in the literature, its use in RO desalination systems has been rarely studied in practice, and therefore, the costs of a large-scale PRO-RO plant are difficult to estimate at this stage. As a rough estimate, investigations conducted by Loeb (2001) found that a PRO plant at the Great Salt Lake could produce $66 \mathrm{MW}$ at a capital cost of US $\$ 9000$ and an energy unit cost of 0.09 US $\$ / k W h$. This cost includes the capital amortisation (0.058 US $\$ / k W h)$, membrane replacement $(0.008$ US $\$ / k W h)$, labour (0.008 US $\$ / k W h)$, and operation and maintenance cost (0.017 US $\$ / k W h)$. This cost, as reported by Achilli and Childress (2010), is comparable to the average retail electricity price in the United States at that time (0.067 US\$/kWh).

\subsection{Water-energy-climate nexus conundrum for sustainable urban water supply}

Without sufficient rainfall, existing reservoirs supplying water to large urban areas are ineffective. Given the inherent uncertainty of climate variability and change, and the changing temporal and spatial patterns of rainfall, a key question is: What can be done to reduce the impact of uncertainty and provide 
the long-term water security required to cope with the water scarcity problems caused by a changing climate and population growth? Rain-independent options such as $\mathrm{RO}$ desalination prossess have issues of their own, owing to their energy intensive nature, leading to problematic energy, climate and cost implications.

This water-energy-climate nexus is evidently complex and requires a planning process that accounts for the interdependencies, feedbacks and non-linear relationships between the relevant water, energy and climate variables. Adapting the bulk water supply portfolio so that large urban centres can reliably handle future projections of rapid population growth, economic growth, reduced rainfall reliability, increased air temperatures and lower reservoir inflow, while concurrently mitigating GHG impacts of rain-independent supply sources via integration with renewable energies, will have significant cost implications that need to be considered by policymakers and communicated clearly to the public.

In this context, by using the SEQ case, this paper focuses on evaluating the water balance of the bulk water supply system for a number of future water supply source scenarios over a 100 year time horizon. The primary goal is to examine and compare potential infrastructure and management solutions for the water-energy-climate conundrum faced by SEQ, including the implementation of dual purpose PRO equipped RO desalination plants.

\section{APPROACH}

\subsection{Systems Approach and System Dynamics Modelling}

In this research, system dynamics (SD) modelling is applied to investigate the water system in SEQ. The attributes of SD, specifically its ability to accommodate feedbacks, interdependencies, and nonlinear relations, align strongly with the objectives of this paper of assessing the water-energy-climate change nexus for SEQ.

SD is a powerful methodology and computer simulation modelling approach, which emerged from the management and engineering sciences (Forrester, 1961). Gradually, the SD approach has evolved and 
spread into other fields to simulate complex systems behaviour such as energy and the environment (Fiddaman, 1997); policy and strategy analysis (Sterman, 2000); assessment of coastal vulnerability and the adaptation alternatives (Sahin and Mohamed, 2013); long term planning of water supply augmentation decisions (Scarborough et al., 2015); and exploring the potential for hydropower as a cobenefit in an operating regime for a water reservoir (Sahin et al., 2016b).

\subsection{Model Development}

System diagrams are qualitative models that are important and powerful tools used in systems analysis. They help define the main components of a system by separating endogenous (within the system) and exogenous (external to the system) variables and identifying the resolution of the model. They also help link the structure of a system to its behaviour (e.g. for highlighting why increased water extraction causes increased energy demand and GHG emissions) and facilitate the development of quantitative SD models.

A system diagram represents cause-effect relations between elements or sub-systems of the overall system (Loucks and van Beek, 2005). These cause-effect relations form the building blocks of feedback loops that are responsible for explaining the behaviour of the overall system. Feedback is a process whereby an initial cause ripples through a chain of causation, ultimately to re-affect itself (Roberts, 1983). These feedback loops can interact with other feedback loops leading to complex behaviour of the system. Importantly, the interactions between multiple loops within a system is not linear and an identical change in one component may not always cause the same system behaviour as there may be a change in the state of the system, over time. A sample system diagram used in this project for analysing water resources problems is presented in Figure 2.

Essential variables for model operation were identified by reviewing locally based literature for region specific inputs and examining world literature for more generic variables and their behaviour. System norms and rules were informed by the SEQ Water Strategy Reports in combination with other literature (QWC, 2010, 2012). 


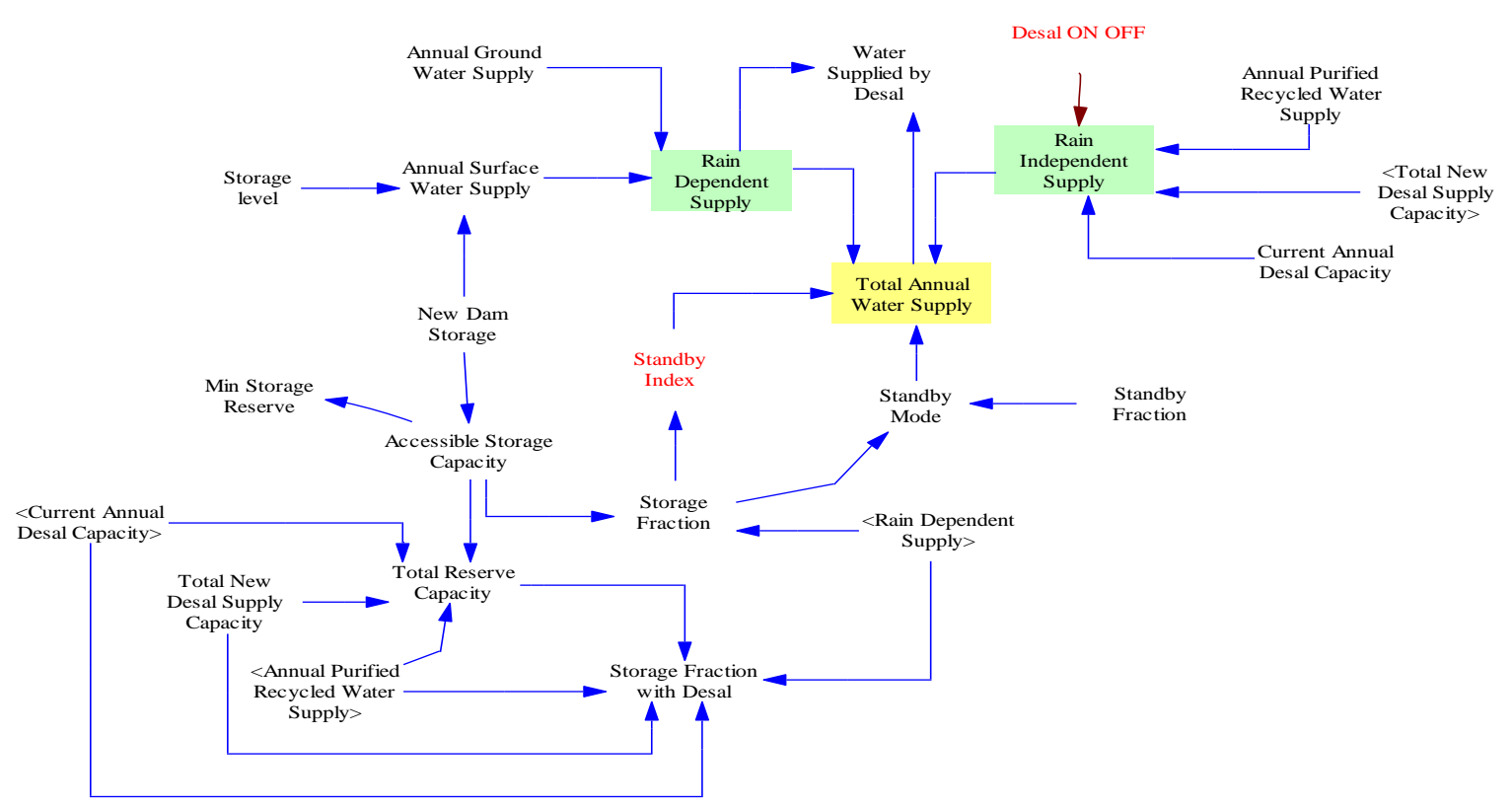

Figure 3 A SD sub-model representing a water supply system

The SD model presented in this paper represents ongoing model development and refinement of earlier versions. The SD model was first developed for desalination and applied to SEQ to explore scarcity pricing (Sahin et al., 2015) and to analyse the potential for pressure retarded osmosis (PRO) technology to generate electricity (Sahin et al., 2016a). This model was subsequently modified for Melbourne (Porter et al., 2014; Scarborough et al., 2015) to explore rain independent desalination versus more traditional rain dependent dams in long-term planning. For further details of these models, the reader is referred to the publications cited above..

Based on these previous studies, the SD model has been customised for simulating the long-term water supply planning in SEQ under a range of scenarios by considering the changing climate, population growth, and the GHG emissions generated by manufactured water. The SD model, using the Vensim ${ }^{\circledR}$ DSS (Ventana Systems, 2016), was built using the following steps: (1) identifying key variables, (2) assuming relationships between these variables and (3) parameterising these relationships. In building the SD model, a participatory modelling approach was employed. Participatory model development can focus on portraying system structure, while model simulations reveal system behaviour, which is less intuitive and often a source of confusion (Vennix et al., 1996; Hovmand, 2014). 
The SD model framework focuses on demand, supply, climate change, population growth, and the resulting water balance when adding a range of future rain-dependent and rain-independent bulk supply sources in the region over a 100 year modelling horizon. This time span was selected in order to undertake long term planning of water supply augmentation decisions by considering energy use and climate adaptation, and understanding the long-term implications of management decisions made by policy-makers. The dynamic nature of the system means that it is important that the system has sufficient time to evolve; shorter time frames might give inaccurate information about future trajectories. It must be acknowledged that during such a long time span, possible policy reforms, social developments and changes in economic and environmental conditions are likely to occur. Therefore, the 100 years is seen as a time bound and the results are presented in a continuous form where changes in the key variables during the time period and at intervening times can be analysed. Further, the water infrastructure investments are capital intensive with a long life span. For a meaningful cost comparison analyses, lower discount rates were used over longer time horizons. This is in line with the literature (Tientenberg and Lewis, 2012).

In summary, this paper encompasses the following steps:

Step 1: Perform a literature review and expert consultations to benchmark the current state of knowledge in modelling parameters relevant to this project; obtain model input data, such as per capita water use, annual water supply capacity of existing water resources, population, historical rainfall data, climate change projections, the parameters of bulk supply source options (i.e. reservoirs, desalination, bulk recycled, etc.), construction and operation costs of different bulk supply alternatives, and their energy-intensity and GHG implications.

Step 2: Build an SD model using the software platform VENSIM ${ }^{\circledR}$ (Ventana Systems, 2016) to simulate the water balance, future bulk supply infrastructure portfolio, life cycle cost and GHG implications for a particular future SEQ bulk supply portfolio. 
Step 3: Analyse the current and future conditions (0-100 years) under a range of scenarios (e.g. different number of new desalination/recycling plants and reservoirs, changes in precipitation due to climate change, increases in water demand, population growth rate, energy supply source, etc.).

Step 4: Examine the GHG implications of resilient bulk water supply portfolios. This is based on the modelled future bulk water supply infrastructure requirements and projections of the needs for future energy intensive rain-independent bulk water supply sources (e.g. desalination) required for the region.

Step 5: Perform an economic analysis to determine the present value of capital and operation costs (\$ $\mathrm{m}^{-3}$ ) of the rain-dependent and rain-independent supply sources that provide sufficient climate resilience for the SEQ region.

\subsection{Baseline Assumptions and Scenarios}

System boundaries are essential in identifying the main variables of the SD model. These main variables required in the SD model were identified through a comprehensive literature review and workshops involving expert consultants, water utilities and researchers (Table 1).

Table 1 The key model input variables and range of values for SEQ water supply-demand system

\begin{tabular}{ll}
\hline Input Variables & Baseline Assumptions \\
\hline Current population (Persons) $\# 1$ & $3.2 \times 10^{6}$ \\
Population growth rate $(\%)^{\# 1}$ & 1.5 (Ranging from -2.5 to 2.5$)$ \\
Water use per capita $\left(\mathrm{L} \mathrm{d}^{-1}\right)^{\# 2, \# 6, \# 7}$ & 300 (Ranging from 200 to 450) \\
Existing reservoir capacity $\left(\mathrm{hm}^{3}\right)^{\# 2}$ & 2,220 \\
Existing desalination capacity $\left(\mathrm{hm}^{3} \mathrm{y}^{-1}\right)^{\# 2}$ & 46 \\
Desalination capital costs $(\$ \mathrm{Billion})^{\# 3, \# 8}$ & 1.2 (Ranging from 1.2 to 5) \\
Desalination operation cost $\left(\$ \mathrm{~m}^{-3}\right)^{\# 3}$ & 0.95 (Ranging from 0.75 to 2.5) \\
Reservoir capital cost $(\$)^{4}$ & 1.7 (Varying from 1 to 5) \\
Reservoir operation cost $\left(\$ \mathrm{~m}^{-3}\right)^{\# 4}$ & 0.15 (Ranging from 0.1-0.3) \\
Modelling time horizon $(\mathrm{y})$ & 100
\end{tabular}


Time interval of simulation $(y)$

Water security index \#5

Discount rate (\%)

Size of new desalination to be constructed $\left(\mathrm{hm}^{3} \mathrm{y}^{-1}\right)$

Size of new reservoir to be constructed $\left(\mathrm{hm}^{3}\right)$
0.25

6 (Ranging from 1 to 6 )

3.5 (Ranging from 1.5 to 5.5 )

50 (Ranging from 50 to 150)

100 (Ranging from 50 to 150 )

\section{Notes:}

\#1 Queensland Office of Economic and Statistical Research (2011);

\#2 QWC (2012); \#3 Stewart (2011); \#4 Moran (2008);

\#5 The water security index is the annual water demand divided by the accessible storage capacity;

\#6 Per capita consumption includes residential and non-residential components;

\#7 300 means an efficient $300 \mathrm{~L} \mathrm{~d}^{-1}$ (200 L d-1 residential $+100 \mathrm{~L} \mathrm{~d}^{-1}$ non-residential plus system losses) demand in present;

${ }^{\# 8}$ Australian dollars (0.740 USD $=1.0$ AUD average for 2016 prices $)$

The SD model assumes that the volume and character of water use is mainly determined by five key drivers with varying effects. These are: Population growth; Desalination plants; Traditional water resources; Climate change and variability; and Changes in water use pattern and demand. Spatial boundaries of the SD model comply with the boundaries of the grid connecting the SEQ bulk water supply system. The stock levels and asset values, such as reservoir volumes and capital values are determined from the modelled and assumed flows and investments per period. The time horizon of the model was selected as 100 years in order to consider the historical long-term cycles of rainfall patterns.

To test whether using desalination is a feasible option, as a way of providing water security during the drought and generating energy during the wet season to offset carbon emission, a range of scenarios have been explored for the next 100 years using the SD model. Three plausible future scenarios of per capita water demand in the SEQ region were used: (1) low demand (300 $\left.\mathrm{L} \mathrm{d}^{-1}\right)$; (2) pre-drought demand (450 L d $\mathrm{d}^{-1}$ ); and (3) the SEQ Level of Service objectives level (375 L d-1). Scenarios to compare the energy requirements, $\mathrm{CO}_{2}$ output and monetary cost of different infrastructure options were developed through varying the level of water security maintained by the system (as expressed through the water security index detailed in Section 3.3) and discount rates of $1.5 \%, 3.5 \%$ and $5.5 \%$. The baseline parameters for desalination capex in Table 1 are reflective of the existing desalination capacity in the 
SEQ region. For example, cost of building a desalination plant with a capacity of $46 \mathrm{hm}^{3} \mathrm{y}^{-1}$ is $\$ 1.2$ billion, which is the lower end of the range presented in Table 1.

\section{$3 \quad$ RESULTS}

The process of model development is further described as part of the Results, reflecting the outcomes of the steps outlined in the previous section.

\subsection{Water Supply and Demand Simulation}

Annual water demand is a function of the Population and Per Capita Water Demand. Therefore, the first step in forecasting annual water demand is estimating the size and future growth of the population in SEQ. The projected annual growth rate averaged over the 45 year period 2011 to 2056 is $1.5 \%$ (Queensland Treasury, 2011). Using this growth rate, the population of the SEQ region was projected to grow from about $3 \mathrm{M}$ to $6.5 \mathrm{M}$ over the next 50 years, and to $13.7 \mathrm{M}$ over the hundred year projection period.

Two variables, Annual Water Demand (ML year-1) and Population (Persons) were computed using the following equations:

$A W D=P \times W D p c$

$P=\int P C h d t+P i$

Where: AWD: Annual Water Demand; P: Population; $P C h \quad$ : Population Change; Pi: Initial Population; and WDpc: Per Capita Water Demand.

\subsection{Desalination Plants and GHG implications: Role of PRO Technology}

Under the three chosen water demand scenarios, Water Demand at the end of 100 -year period ranges from about $1.5 \mathrm{hm}^{3}$ year-1 to $2.26 \mathrm{hm}^{3}$ year-1, as shown in Figure 3 . 


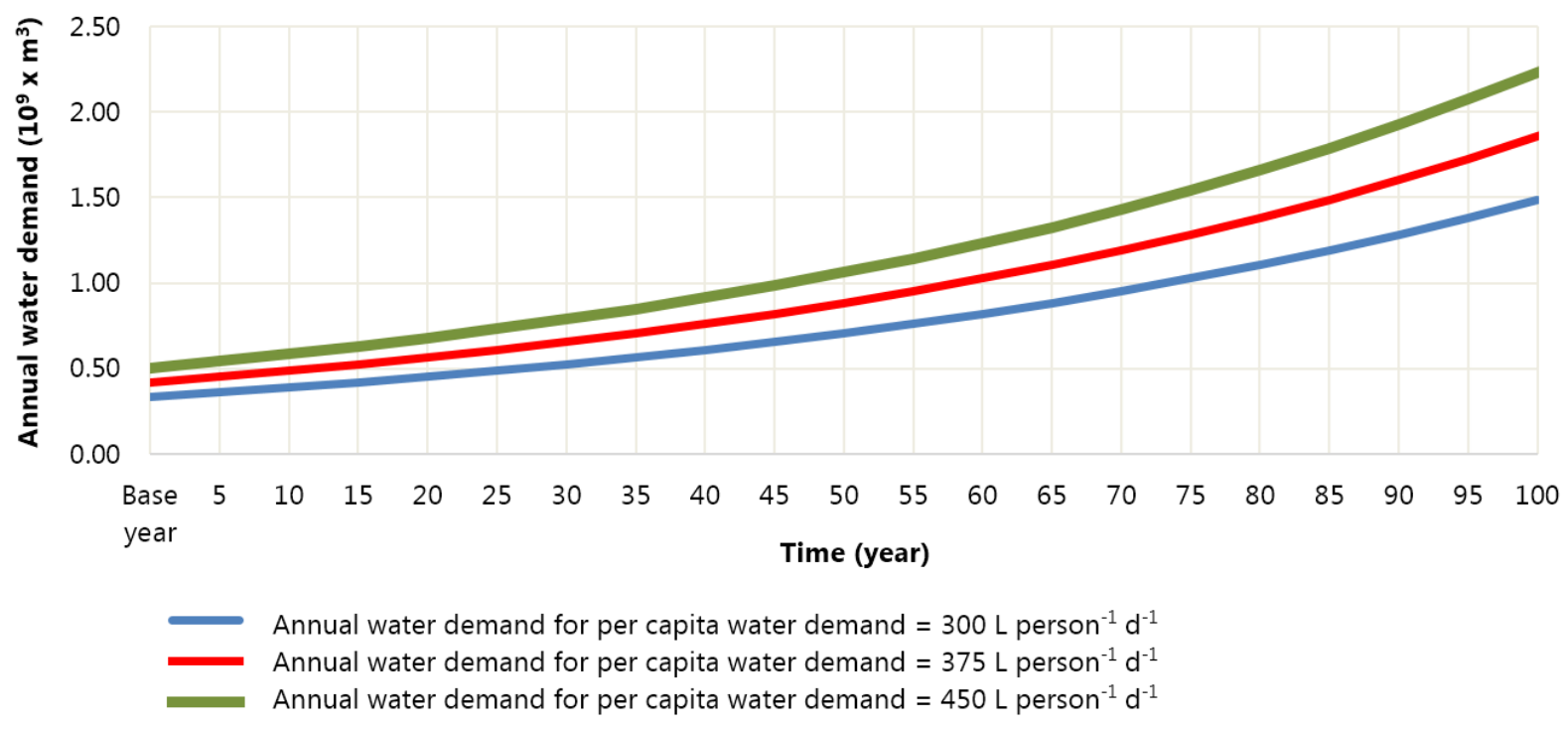

Figure 3 Annual water demand projections under three scenarios of Per Capita Water Demand

As introduced in Section 1.3, PRO technology has the potential to offset the energy requirements of RO desalination plants. With this in mind, the utilisation of $\mathrm{RO}$ desalination plants equipped with a seawaterto-freshwater PRO facility to generate osmotic power was incorporated in the model. The use of desalination plants is controlled by a logic relationship, mirroring the actions of a water governance body (QWC, 2010). It would be counterintuitive to utilise desalination plants to generate electricity in times of water shortage, as this would further contribute to water scarcity. When reservoir levels are in excess of $80 \%$ capacity, desalination plants are used for energy production with PRO. The model reveals that over the 100 year simulation period $\mathrm{RO}$ desalination accounts for $25 \%$ of the total possible utilisation available, while PRO accounts for a higher $66 \%$. The remaining times of non-utilisation (i.e. $9 \%$ ) occur in years where only a portion of full plant capacity is required for $\mathrm{RO}$ desalination to augment water supply.

It is important to note that despite the significant advancements in membrane development observed since the turn of the century, when membrane prices began to fall and membranes started to be improved for PRO applications, the generation of power with PRO were still hindered by the low flux and low resistance of the current membranes (Koroneos et al., 2007; Helfer and Lemckert, 2015). Thus the desalination scenarios proposed in this study, which use the existing desalination infrastructure to 
generate energy via PRO, do not compose a realistic scenario in the present-day context since they are predicated to the maturation of PRO technology.

Emission factors for calculating direct emissions are generally expressed in the form of a quantity of a given GHG emitted per unit of energy. CommLaw (2013) defines indirect emissions (Scope 2) as the emissions which are physically produced by the burning of fuels (coal, natural gas, etc.) at the power station, and projects the Indirect Emissions Factors for Queensland as $0.82 \mathrm{~kg} \mathrm{CO}_{2} \mathrm{e} \mathrm{kWh}{ }^{-1}$ (Note: $\mathrm{CO}_{2} \mathrm{e}=$ carbon dioxide equivalent). Indirect emission factors were used to calculate $\mathrm{CO}_{2}$ emissions from the generation of the electricity, or consumed by desalination as t of $\mathrm{CO}_{2} \mathrm{e}$ per GWh of electricity used, or generated.

The simulation results (Figure 4) show that at the end of 100 year simulation period, the use of PRO has the potential to generate enough energy (15,400 GWh) to counterbalance the energy used for water production (11,300 GWh), and offset $100 \%$ of the $\mathrm{CO}_{2}$ generated during freshwater production.

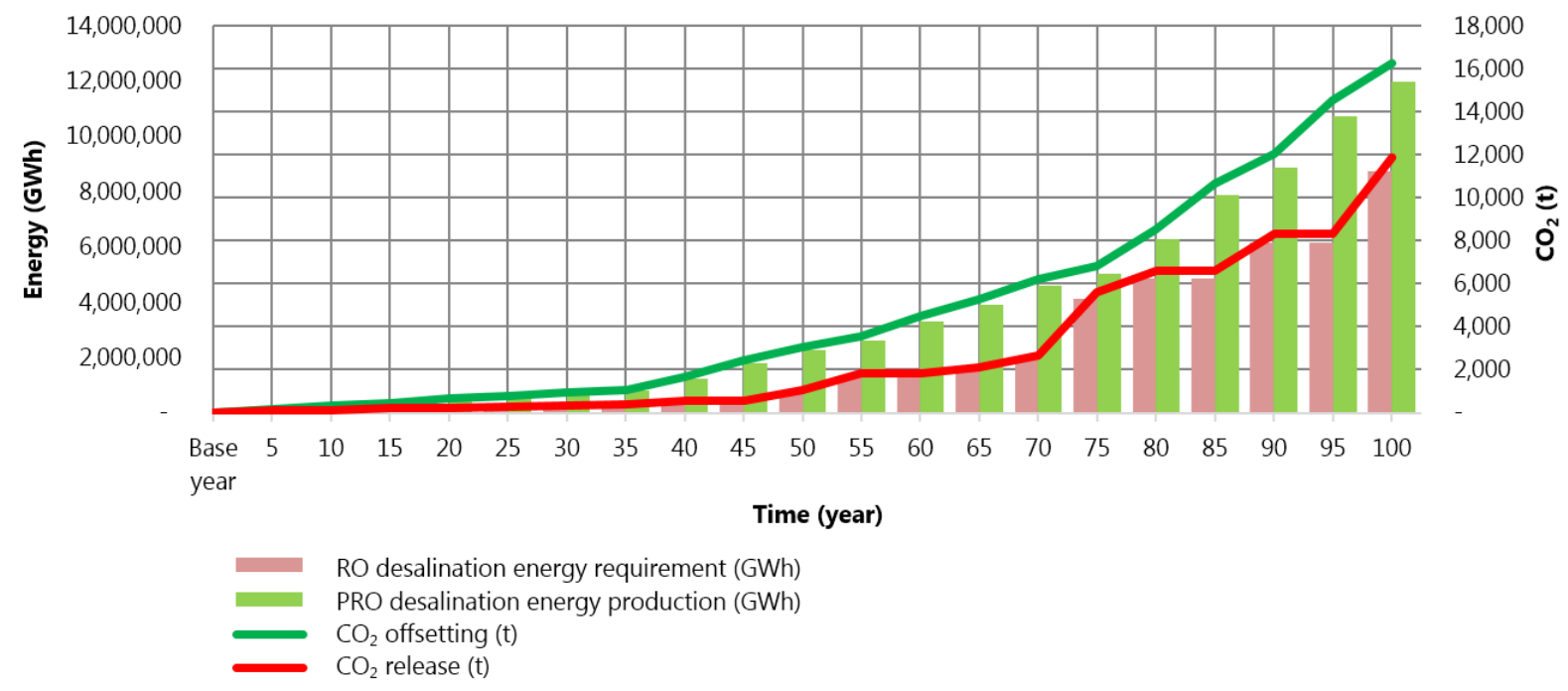

Figure 4 Energy and $\mathrm{CO}_{2}$ used and offset by Desalination through PRO technology

\subsection{Comparison of Water Supply Options}

Using the SD model, additional storage capacity to maintain current water security level in the region was calculated. Since the accessible volume of water at any given time is one of the most important 
factors affecting water security, an indicator of water supply security used in this research is the water security index (WSI). This index reflects the ratio of water storage to annual demand, and therefore, storage buffer required against low rainfall years. Marsden and Pickering (2006) reported that the ratio of storage to annual usage in SEQ is six. Given this baseline value, required new infrastructure investments for desalination plants and reservoirs were calculated over the simulation period. The results show the need for long term planning to meet the challenges of likely water shortfalls between demand and supply. As SEQ's population increases from the current 3.2 $\mathrm{M}$ to a projected $13.6 \mathrm{M}$, the total additional water supply required over the projected 100 year period could increase by 5,000 GL for the low demand scenario. Total additional water supply required under a WSI of 5 and 4 were also simulated, a higher risk management approach, as a point of comparison. Finally, Net Present Values (NPV) of the rain-dependent and independent supply options by considering capital and operation costs were calculated to compare the economic viability of these two options.

The impact of social discount rates of $1.5 \%, 3.5 \%$ and $5.5 \%$ have been explored. The Australian government recommends a social discount rate of $7 \%$ with sensitivity analysis at $3 \%$ and $11 \%$ (Scarborough et al., 2015). However, lower rates have been used in the sensitivity analysis in line with the literature which suggests that lower discount rates are more appropriate over longer time horizons (Weitzman, 1998; Harrison, 2010; Weitzman, 2013). There is also literature to suggest that lower social discount rates are more appropriate for public projects given the lower risk and diversity of risk profile associated with public sector investments (Tientenberg and Lewis, 2012). 


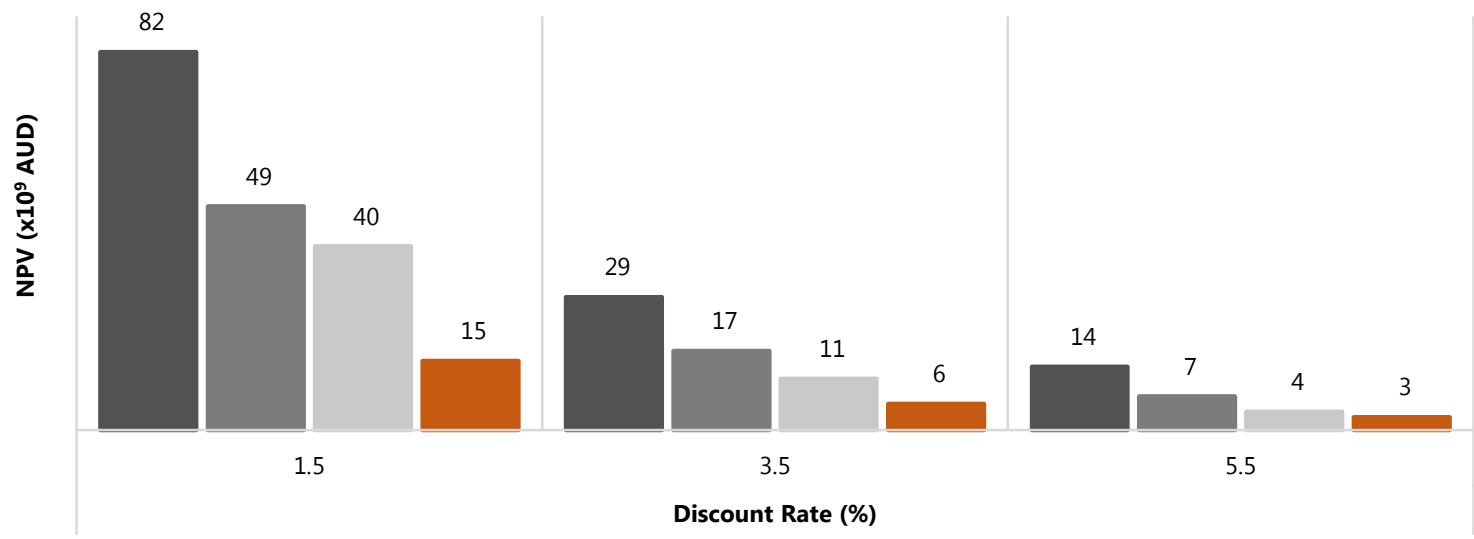

NPV of total reservoir infrastructure required new capacity under WSI6 NPV of total reservoir infrastructure required new capacity under WSI5 NPV of total reservoir infrastructure required new capacity under WSI4 NPV of total desalination infrastructure required new capacity under WSI6

Figure 5 NPV comparisons of rain-dependent and independent supply options under varying discount rates and WSI

Figure 5 shows the sensitivity of the results of the comparison of water supply augmentation costs between reservoir construction and investing in desalination capacity (including both operating and capital investment costs).

As illustrated in Figure 5, under a WSI of 6 and a 1.5\% discount rate, the NPV of new reservoir infrastructures would be approximately 82 billion Australian dollars, about five times larger than the NPV of the desalination plants infrastructure. This ratio is maintained across the other discount rate scenarios. Even when the WSI is reduced to 4, the NPV of RO desalination plant cost is less than reservoir cost. 


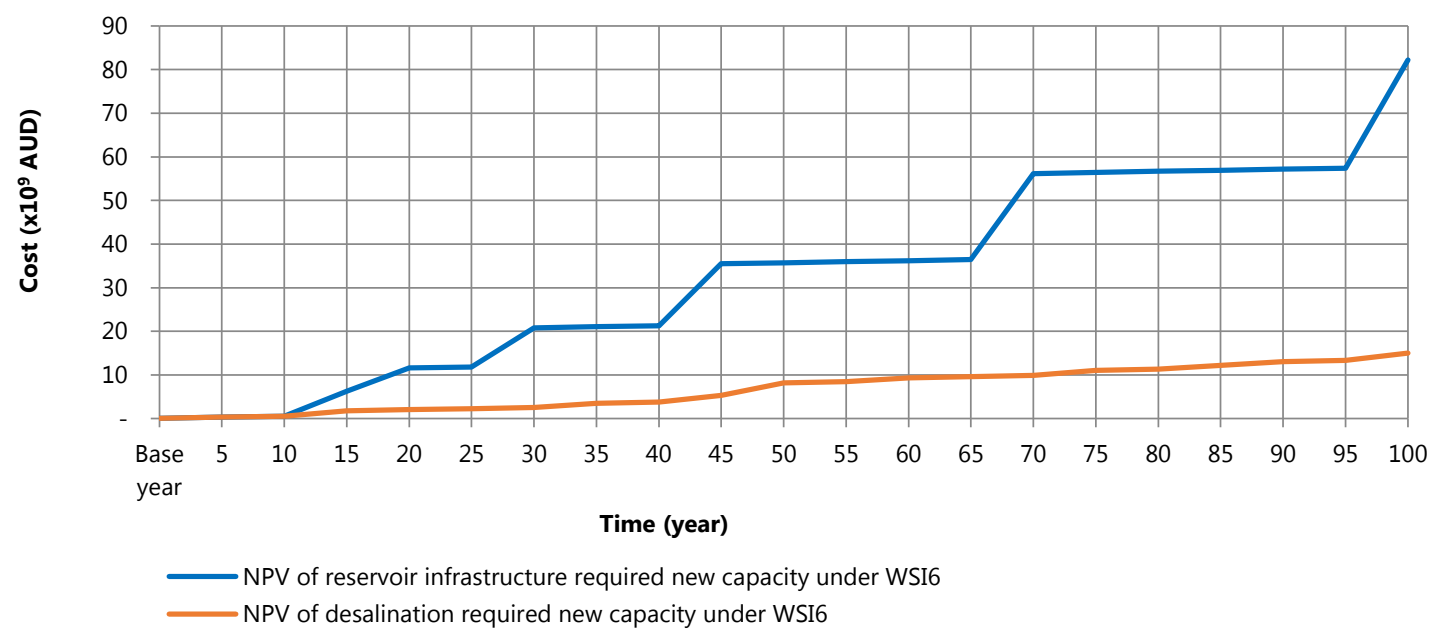

Figure 6 NPV comparison of rain-dependent and independent supply options under WSI 6 with a discount rate of $1.5 \%$

Figure 6 shows how the rain-dependent and independent supply costs develop over the simulation period. In the first 10 years costs are very similar. After 10 years the cost of desalination investment in water supply augmentation is considerably lower than the cost of reservoir construction. Noticeably, over the longer time horizon, the cost comparison changes to become greatly in favour of desalination. While the rain-independent nature of desalination plants means that a lower NPV than surface water can be achieved in the SEQ region, current RO technology is energy intensive and contributes negatively to climate change. Potentially, PRO-technology enabled desalination plants provide an opportunity to sustainably provide lowest cost water security infrastructure that offsets its carbon emissions.

\section{DISCUSSION}

The development of an SD model built to explore the behaviour of the SEQ water resource system over the next 100 years under systemic change brought about by climate change and population growth has been detailed. The model includes the management option to adopt a portfolio approach, mixing desalination and reservoir infrastructure to meet growing demand over the simulation period. A portfolio 
approach requires consideration of both water energy nexus in terms of risks and costs of each water supply option.

In order for reservoir infrastructure to provide water security, a high ratio of capacity relative to annual demand is required, as represented by the WSI. This becomes increasingly expensive, and as shown in SEQ, could become prohibitively expensive under anticipated demand increases. Therefore, rainindependent supply options must be considered in comparison.

Through SD modelling, it has been demonstrated that desalination plants may be a useful insurance policy to deal with uncertainty surrounding water supply resources due to high rainfall variability. However, like any insurance policy, standard RO desalination plants would be forced to sit idle for great lengths of time, only called into action intermittently. Moreover, due to the type of technology used in the desalination process, the energy intensity of current Australian desalination plants is up to 10 times greater than the energy presently consumed in supplying bulk water in SEQ (Kenway et al., 2008; Hoang et al., 2009; White, 2009). These factors raise two significant arguments against their implementation in the country: utilisation efficiency of desalination plants and high energy needs.

In this context, the continuing advent of PRO technology could greatly nullify these problems and provide other supplementary benefits. For existing desalination plants, a conjugated PRO facility to generate power could be an option, as suggested by (Helfer et al., 2014). The technical similarities between desalination and osmotic power could easily justify the investment on PRO plants. Even better, provided technical issues are overcome in membrane development, another option could be replacing existing single-purpose $\mathrm{RO}$ membranes with dual-purpose membranes (i.e. membranes able to work under $\mathrm{RO}$ and PRO conditions), thereby transforming $\mathrm{RO}$ desalination plants into dual-purpose water supply and renewable energy production facilities. Additional power generation capacity would also decrease the need for fossil fuel exploitation, or the development of other renewable power supply plants.

Clearly, there are numerous potential benefits of integrating the PRO technology into the operation of water resource systems that utilise desalination as one of the supply alternatives, such as the SEQ 
region's water system. Bulk water portfolio diversification would increase security of supply despite drought. Economic and environmental risk both fall with a mix of desalination and surface water. Evidently, there will be costs due to desalinated water due to its relative energy intensity. However, when the mix of water supply is costed over a century of rainfall cycles as presented in this paper, it becomes clear that reliable long-term contracts for water supply will probably be cheaper and more secure with less new dams and more desalination.

The SD model applied in this study indicates that under predicted future SEQ climatic conditions, desalination plants will be inactive for sufficient periods of time to allow generation of nearly half the energy consumed in manufacturing water. Thus, depending on capital costs (which are difficult to estimate at this stage due to the inexistence of large-scale PRO-assisted RO plants from which real costs could be derived), the investment in PRO technology in the future could be worthwhile in SEQ.

It has been demonstrated that the SD framework allows rapid evaluation of the effects of a range of management scenarios through providing realistic visualisation of how water supplies and demands could change over time. Therefore, the framework would improve decision makers' ability to develop sustainable water resource management and planning strategies, and thus respond to water scarcity in a timely manner to optimise supplies given the various constraints.

\section{CONCLUSIONS}

A key conclusion emerging from this study is that a systems approach is an effective methodology for understanding system behavior because it accounts explicitly for the feedback paths, interdependencies and non-linearities that characterise these and many other types of systems. Most other common methodological approaches cannot sufficiently account for the characteristics of the urban water system and effectively evaluate the utility of a portfolio approach across a range of indicators (i.e. GHG emissions, energy use, water demand) and over an extended period of time (100 years). 
Another key conclusion from this analysis of the SEQ bulk water supply system rainfall, investment, population, $\mathrm{CO}_{2}$ offsetting and PRO technology options is that desalination can theoretically deliver lower long-term average costs than a reliance on reservoirs while delaying the investment (or need) for large scale reservoirs. Moreover, that an emerging PRO technology may help to overcome many of the drawbacks of traditional RO desalination plants, by making them more sustainable in terms of energy consumption and effective plant utilisation. Water demand and security needs can be met as the population and economy expand by considering rainfall volatility and drought. These are surmountable challenges, which can be managed through a portfolio approach to water supply.

The context of the paper's water security assessment is not unique to SEQ, or Australia. Therefore, owing to the use of a system dynamics approach, the model detailed in this study can provide a framework for assessing water security for many situations where a water-energy-climate nexus conundrum exists.

\subsection{Limitations}

The following limitations should be considered when utilising the findings of this study:

- There is no consideration given to decision making processes of government and water management bodies and the political practicalities of the infrastructure portfolio in the modelled scenarios;

- PRO is not a mature technology and is only at the early stages of its development. To this end, significant technological advancement is required before a large scale hybrid PRO-RO plant can be built like those included in the modelled scenarios of this study. However, research such as the current study (in conjunction with the technological research and development) is a necessary step in advancing PRO towards large scale deployment;

- The modelling parameters relating to PRO reflect the best available data from laboratory studies conducted to date. It is likely that as the technology is further developed and economies 
of scale are achieved, the power generation rates from PRO will increase and in this case, simulations should be re-conducted with updated parameters;

- There are other desalination technologies that could have been considered in this study. However, the predominant desalination technology in Australia is RO desalination (68\%), which is also the fastest growing desalination technology in the world. In Queensland, where this study was undertaken, $\mathrm{RO}$ desalination is responsible for $90 \%$ of the desalinated water. Therefore, only RO was considered in this study.

- The available population growth projection by the Queensland government covers only the next 45 years starting from 2011. In this research, a 100-year time horizon was used for simulation. Therefore, in order to cover the remaining period, it was assumed that the population growth rate would remain the same.

\section{ACKNOWLEDGMENTS}

Sincere thanks to the Griffith Climate Change Response Program (GCCRP) for facilitating the creation of this model through the seed funding initiative and supporting its continued development through the Griffith Systems Modelling Group. The support provided by the Conselho Nacional de Desenvolvimento Científico e Tecnológico (CNPq, Brazil) to Dr Fernanda Helfer through the research grant number $203576 / 2014-4$ is acknowledged.

\section{REFERENCES}

ABS, 2012. 2012 Year Book Australia. The Australian Bureau of Statistics, Canberra, Australia.

Achilli, A., Childress, A.E., 2010. Pressure retarded osmosis: From the vision of Sidney Loeb to the first prototype installation - Review. Desalination 261, 205-211.

CommLaw, 2013. National Greenhouse and Energy Reporting (Measurement) Determination 2008. Office of Legislative Drafting and Publishing, Attorney-General's Department.

Department of Industry and Science, 2015. Australian Energy Update, Canberra, Australia. 
El Saliby, I., Okour, Y., Shon, H.K., Kandasamy, J., Kim, I.S., 2009. Desalination plants in Australia, review and facts. Desalination 247, 1-14.

Elimelech, M., Phillip, W.A., 2011. The Future of Seawater Desalination: Energy, Technology, and the Environment. Science 333, 712-717.

Fiddaman, T., 1997. Feedback Complexity in Integrated Climate-Economy Models, Alfred P. Sloan School of Management. Massachusetts Institute of Technology, Cambridge, MA, USA.

Ford, A., 1999. Modelling the Environment: An Introduction to System Dynamics Modelling of Environment Systems. Island Press, Washington DC, USA.

Forrester, J.W., 1961. Industrial dynamics, (Students' edition) ed. MIT Press, Cambridge, MA, USA.

Harrison, M., 2010. Valuing the future : the social discount rate in cost-benefit analysis : visiting research paper. Productivity Commission, Melbourne, Australia.

Hatton, T., Cork, S., Joy, P.H.R., Kanowski, P., Mackay, R., McKenzie, N., Ward, T., Wienecke, B., 2011. State of the Environment. The Department of Sustainability, Environment, Water, Population and Communities, Canberra, Australia.

Hejazi, M., Edmonds, J., Clarke, L., Kyle, P., Davies, E., Chaturvedi, V., Wise, M., Patel, P., Eom, J., Calvin, K., Moss, R., Kim, S., 2014. Long-term global water projections using six socioeconomic scenarios in an integrated assessment modeling framework. Technological Forecasting and Social Change 81, 205-226.

Helfer, F., Lemckert, C., 2015. The power of salinity gradients: An Australian example. Renew Sust Energ Rev 50, 1-16.

Helfer, F., Lemckert, C., Anissimov, Y.G., 2014. Osmotic power with Pressure Retarded Osmosis: Theory, performance and trends - A review. J Membrane Sci 453, 337-358.

Helfer, F., Lemckert, C., Zhang, H., 2012. Impacts of climate change on temperature and evaporation from a large reservoir in Australia. Journal of Hydrology 475, 365-378.

Helfer, F., Sahin, O., Lemckert, C., Anissimov, Y., 2013. Salinity gradient energy: a new source of renewable energy in Australia. Water Utility Journal 5, 3-13.

Hoang, M., Bolto, B., Haskard, C., Barron, O., Gray, S., Leslie, G., 2009. Desalination in Australia, Water for a Healthy Country Flagship Report series ISSN: 1835-095X. CSIRO, Clayton, Victoria, Australia.

Hovmand, P.S., 2014. Community based system dynamics. Springer, New York, NY, USA. 
IDA, 2015. Desalination by the numbers. International Desalination Association,, Topsfield, USA.

IEA, 2014. World Energy Outlook. International Energy Agency, Paris, France.

IPCC, 2014a. Climate Change 2014: Impacts, Adaptation, and Vulnerability. Part B: Regional Aspects. Contribution of Working Group II to the Fifth Assessment Report of the Intergovernmental Panel on Climate Change, in: Barros V.R, C.B.F., D.J. Dokken, M.D. Mastrandrea, K.J. Mach, T.E. Bilir, M. Chatterjee, K.L. Ebi, Y.O. Estrada, R.C.Genova, B. Girma, E.S. Kissel, A.N. Levy, S. MacCracken, P.R. Mastrandrea, White, L.L. (Eds.). Cambridge University Press, Cambridge, United Kingdom and New York, NY, USA, p. 688.

IPCC, 2014b. Climate Change 2014: Synthesis Report. Contribution of Working Groups I, II and III to the Fifth Assessment Report of the Intergovernmental Panel on Climate Change, in: Core Writing Team, Pachauri, R.K., Meyer, L.A. (Eds.), Geneva, Switzerland, p. 151.

Kenway, S.J., Priestly, A., Cook, S., Seo, S., Inman, M., Gregory, A., Hall, M., 2008. Energy use in the provision and consumption of urban water in Australia and New Zealand, Water for a Healthy country Flagship. CSIRO, Canberra, Australia.

Koroneos, C., Dompros, A., Roumbas, G., 2007. Renewable energy driven desalination systems modelling. Journal of Cleaner Production 15, 449-464.

Lazarus, R.J., 2009. Super wicked problems and climate change: Restraining the present to liberate the future. Cornell Law Review 94, 1153-1233.

Loeb, S., 2001. One hundred and thirty benign and renewable megawatts from Great Salt Lake? The possibilities of hydroelectric power by pressure-retarded osmosis. Desalination 141, 85-91.

Loucks, D.P., van Beek, E., 2005. Water resources systems planning and management : an introduction to methods, models and applications. Unesco, Paris, France.

Marsden, J., Pickering, P., 2006. Securing Australia's urban water supplies opportunities and impediments. Marsden Jacob Associates, Camberwell, VIC, Australia, pp. xi, 58 p.

Moran, A., 2008. Water supply options for Melbourne - An examination of costs and availabilities of new water supply sources for Melbourne and other urban areas in Victoria. Institute of Public Affairs, Melbourne, Australia.

OECD, 2015a. Environment at a Glance 2015. OECD Publishing, Paris, France.

OECD, 2015b. OECD.stat Greenhouse Gas Emissions. 
Pittock, J., Connell, D., 2010. Australia Demonstrates the Planet's Future: Water and Climate in the Murray-Darling Basin. International Journal of Water Resources Development 26, 561-578.

Porter, M.G., Downie, D., Scarborough, H., Sahin, O., Stewart, R.A., 2014. Drought and Desalination: Melbourne water supply and development choices in the twenty-first century. Desalination and Water Treatment 55, 2278-2295.

Post, D.A., Teng, J., Chiew, F., Wang, B., Vaze, J., Marvanek, S., Franks, S.W., Boegh, E., Blyth, E., Hannah, D.M., K.K.Yilmaz, 2011. Non-linearity of the runoff response across southeastern Australia to increases in global average temperature, in: Franks, S.W., Boegh, E., Blyth, E., Hannah, D.M., Yilmaz, K.K. (Eds.), Hydro-Climatology: Variability and Change. International Association of Hydrological Sciences, Oxfordshire, United Kingdom, pp. 188-194.

Productivity Commission, 2011. Australia's Urban Water Sector, Canberra, Australia.

Queensland Office of Economic and Statistical Research, 2011. Local government areas : Queensland Government population projections to 2031, 2011 ed. Office of Economic and Statistical Research, City East, QLD, Australia.

Queensland Treasury, 2011. Population projections to 2031: local government areas, in: The Queensland Treasury - Office of Economic and Statistical Research Demography and Planning (Ed.), 2011 ed.

QWC, 2010. South East Queensland water strategy. Queensland Water Commission, City East, QLD, Australia.

QWC, 2012. South East Queensland Water Strategy - Annual Report 2012. Queensland Water Commission, City East, QLD, Australia.

Roberts, N., 1983. Introduction to computer simulation : the system dynamics approach. AddisonWesley, Reading, MA, USA.

Sahin, O., Mohamed, S., 2013. A spatial temporal decision framework for adaptation to sea level rise. Environmental Modelling \& Software 46, 129-141.

Sahin, O., Siems, R.S., Stewart, R.A., Porter, M.G., 2016a. Paradigm shift to enhanced water supply planning through augmented grids, scarcity pricing and adaptive factory water: A system dynamics approach. Environmental Modelling \& Software 75, 348-361. 
Sahin, O., Stewart, R.A., Giurco, D., Porter, M.G., 2016b. Renewable hydropower generation as a cobenefit of balanced urban water portfolio management and flood risk mitigation. Renewable and Sustainable Energy Reviews 10.1016/j.rser.2016.01.126.

Sahin, O., Stewart, R.A., Porter, M.G., 2015. Water security through scarcity pricing and reverse osmosis: a system dynamics approach. Journal of Cleaner Production 88, 160-171.

Scarborough, H., Sahin, O., Porter, M., Stewart, R., 2015. Long-term water supply planning in an Australian coastal city: Dams or desalination? Desalination 358, 61-68.

Schallenberg-Rodríguez, J., Veza, J.M., Blanco-Marigorta, A., 2014. Energy efficiency and desalination in the Canary Islands. Renewable and Sustainable Energy Reviews 40, 741-748.

SEQ Water, 2016. Latest Dam Levels. SEQ Water, Brisbane, Australia.

Siirola, J.J., 2014. Speculations on global energy demand and supply going forward. Current Opinion in Chemical Engineering 5, 96-100.

Sterman, J., 2000. Business dynamics : systems thinking and modeling for a complex world. Irwin/McGraw-Hill, Boston.

Sterman, J.D., 2008. Economics. Risk communication on climate: mental models and mass balance. Science 322, 532-533.

Stewart, R., 2011. Verifying the end use potable water savings from contemporary residential water supply schemes, Waterlines report No 61. National Water Commission Waterlines Report No. 61, Australian Government, Canberra.

Straub, A.P., Deshmukh, A., Elimelech, M., 2016. Pressure-retarded osmosis for power generation from salinity gradients: is it viable? Energy \& Environmental Science 9, 31-48.

Thorsen, T., Holt, T., 2009. The potential for power production from salinity gradients by pressure retarded osmosis. J Membrane Sci 335, 103-110.

Tientenberg, T., Lewis, L., 2012. Environmental and Natural Resource Economics,, 9th ed. Pearson, Upper Saddle River, NJ, USA.

Turner, A., Sahin, O., Giurco, D., Stewart, R., Porter, M., 2016. The potential role of desalination in managing flood risks from dam overflows: the case of Sydney, Australia. Journal of Cleaner Production In Press dx.doi.org/10.1016/j.jclepro.2016.05.128 Date of last access: 23rd September 2016.

UN, 2015. Transforming our world: the 2030 Agenda for Sustainable Development. United Nations General Assembly, New York, NY, USA. 
UNDESA, 2013. World Population Prospects: The 2012 Revision. United Nations Department of Economic and Social Affairs, New York, NY, USA.

UNESCO, 2012. Groundwater and Global Change: Trends, Opportunities and Challenges. United Nations Educational, Scientific and Cultural Organization Paris, France.

Vennix, J.A.M., Akkermans, H.A., Rouwette, E.A.J.A., 1996. Group model-building to facilitate organizational change: An exploratory study. Syst Dynam Rev 12, 39-58.

Ventana Systems, 2016. Vensim DSS, 6.4 ed. Ventana Systems, Inc., Harvard, MA.

Weitzman, M.L., 1998. Why the far-distant future should be discounted at its lowest possible rate. J Environ Econ Manag 36, 201-208.

Weitzman, M.L., 2013. Tail-Hedge Discounting and the Social Cost of Carbon. Journal of Economic Literature 51, 873-882.

White, I.W., 2009. Decentralised Environmental Technology Adoption: The household experience with rainwater harvesting. PhD Griffith University, Brisbane, Australia.

Willis, R.M., Stewart, R.A., Giurco, D.P., Talebpour, M.R., Mousavinejad, A., 2013. End use water consumption in households: impact of socio-demographic factors and efficient devices. Journal of Cleaner Production 60, 107-115.

Winter, T., Pannell, D., McCann, L., 2002. The Economics of Desalination and its Potential Application to Australia, Research Profile: School of Agricultural and Resource Economics at the University of Western Australia in 2002. Uniprint, The University of Western Australia, pp. 155-164.

World Bank, 2016. High and Dry: Climate Change, Water, and the Economy Washington, DC, USA. License: Creative Commons Attribution CC BY 3.0 IGO. Available: openknowledge.worldbank.org/handle/10986/23665 Date of last access: 23rd September 2016.

World Economic Forum Water Initiative, 2011. National Security, Water Security : The Water-FoodEnergy-Climate Nexus. Island Press/Center for Resource Economics, Washington DC, USA, pp. 88110.

WWAP, 2014. World Water Development Report 2014: Water and Energy. UNESCO World Water Assessment Programme, Paris, France.

WWAP, 2015. Water for a Sustainable World, The United Nations World Water Development Report 2015: Water for a Sustainable World. UNESCO, Paris, France. 
